\title{
The evolutionary history of Drosophila buzzatii. XIV. Larger flies mate more often in nature
}

\author{
M. Santos, \\ A. Ruiz, \\ A. Barbadilla, \\ J. E. Quezada-Diaz, \\ E. Hasson* and \\ A. Fontdevila
}

Departamento de Genética y Microbiología, Universidad Autónoma de Barcelona, 08193 Bellaterra (Barcelona), Spain.

Body size of wild mating males and females of the cactophilic species Drosophila buzzatii was larger and tended to be less variable than that of randomly sampled flies. The intensity of sexual selection was estimated to be $0 \cdot 34$ in males and $\mathbf{0 . 1 6}$ in females (average $\mathbf{0 . 2 5}$ ). Coefficients of rank correlation for the body size of mating pairs are not statistically different from 0 , pointing out that no significant assortment for size occurs in our sample. The results can be interpreted as due to the vigour or general activity levels of larger flies which are more likely to encounter suitable mates than smaller ones, although differences in size could exist among age-classes.

\section{INTRODUCTION}

Darwinian tradition distinguishes between natural and sexual selection (Darwin, 1871). The latter is viewed as a selective process due to variance in mating success and the former as a consequence of variance in other fitness components (Lande, 1980; O'Donald, 1980; Wade and Arnold, 1980; Arnold, 1983; Arnold and Wade, 1984b). This is both a biologically and statistically useful distinction and can explain the origin of sexually dimorphic characters that may sometimes be disadvantageous under ordinary, natural selection, i.e., characters that probably impair survival. However, there is not a crucial distinction between these two selective processes in so far as we are concerned with measurements of selection through a generation, and split up the total selection into various components or episodes (Prout, 1971; Bundgaard and Christiansen, 1972; Arnold and Wade, $1984 a, b$; Ruiz et al., 1986), so that sexual selection can be treated as an aspect of the general process of natural selection (Endler, 1986). Two types of sexual selection mechanisms may act in the population: (1) intrasexual selection, involving compe-

* G.I.B.E. Departamento de Ciencias Biológicas, F.C.E. y N., U.B.A. Pabellón 2, $4^{\circ}$ piso, Ciudad Universitaria Núñez, 1428. Buenos Aires, Argentina. tition of (usually) males for the possession of females; and (2) intersexual selection, involving the exercise of (usually) female choice for mates. The main objections to the Darwinian theory of sexual selection have been focussed on the latter, yet there are experimental evidences that females may choose between males (Semler, 1971; Thornhill, 1976, 1980, 1983; Andersson, 1982; Majerus et al., 1982; Searcy, 1982; Majerus, 1986; Read, 1986; Houde, 1987).

Most empirical studies of sexual selection, mainly in invertebrates, have been conducted in the laboratory and relatively few investigations have been made in natural populations (see below for a review of field studies). This circumstance is most dramatically illustrated in the genus Drosophila where a lavish literature on experimental populations (reviewed in Spiess, 1970; Spieth and Ringo, 1983; Knoppien, 1985) contrasts markedly with a scant knowledge of the natural situation. However thorough they are, laboratory studies might be of little relevance since it is by no means clear to what extent they reflect real field behaviour (Ewing, 1983; Ewing and Ewing, 1984). On the other hand, a number of difficulties are encountered when the study of sexual selection is attempted in the wild (Eanes et al., 1977). Yet, this only supports Endler's (1986, p. 125) statement: "There is no substitute for careful and intensive 
field work if one wants to find out what is happening in natural populations". As far as we are aware, the only field study with Drosophila species has been recently carried out by Partridge et al. (1987; but see Taylor et al. 1987, p. 727). These authors conclude that large males of $D$. melanogaster and $D$. pseudoobscura have a mating advantage and outcompete small males for copulations, and their data suggest that $D$. melanogaster mating females are less variable for body size than non-mating ones.

The advantages offered by the cactophilic species Drosophila buzzatii for the measurement of selection in natural populations were first noted by Barker (1977) and actual examples are already available. Barker and East (1980) showed significant selection associated with allozyme markers in this species by means of the artificial perturbation of an isolated population. Similarly, we were able to detect viability differences among secondchromosome karyotypes in a natural population of Spain using a detailed scheme of sampling through the life-cycle (Ruiz et al., 1986; Santos et al., in press). In this paper we report the results of an analysis of the relationship between thorax length, as a measure of body size, and sexual selection, carried out in the same population. This work was undertaken as a part of a long term study to understand the way selection works on inversions and quantitative characters in the natural populations of $D$. buzzatti. To be more specific, we address here two basic questions: (1) Are mating flies larger and/or less variable for body size than non-mating ones? and (2) Is body size an important variable in predicting mate choice? As the title of the paper anticipates, only the answer to the first question was affirmative.

\section{MATERIAL AND METHODS}

The present study was carried out in the summer 1987 in an old O. ficus-indica plantation located near Carboneras, S.E. Spain (for details see Ruiz et al., 1986). At this time of the year, D. buzzatti breeds exclusively in the decaying Opuntia cladodes. The plot was divided in nine sections of approximately the same area with one randomly chosen collecting site in each. A few rotting Opuntia cladodes per section were located and moved not many meters to the collecting site where they were arranged in the shade. For five consecutive days (25-29 June 1987) the flies attracted to the daily collected rots were observed and a sample of mating and non-mating flies from each site was taken. Collections were made in the evening (from 19:00 to $21: 00$ hours) when adults of $D$. buzzatii showed their maximum activity and could be found in abundance feeding on or flying around the rots. Numerous courtships were observed but usually only a small fraction of them led to copulation. Mating behaviour had been previously studied in our laboratory (Roig et al., 1986) and a brief description follows. As soon as a male notices a female, he approaches her using one or both wings to transmit visual or acoustic stimuli, he strokes the head, thorax and sometimes the abdomen of the female with the forelegs and licks her genitalia with the proboscis. The female may reject him by walking, running or flying away, or may stand still and slightly part her wings, thus enabling the male to mount.

During field collections, we observed a high proportion of wild males attempting to copulate repeatedly in absence of female's acceptance postures and, in some cases, a male was able to mount a female for a short period till the unreceptive female rejected him and flew away. Despite the apparent low receptivity of the females to male copulation attempts, up to 20-25 mating pairs were collected per day per person with a reasonable effort. Copulation time in $D$. buzzatii ranges from about 1 to 3 minutes (Patterson, 1947; Spieth, 1952; Barker and Fredline, 1985) and a mating was assumed to take place if the male mounted in the normal position and remained there for at least 20 seconds. Mating pairs could be gently aspirated without disturbing the surrounding flies by use of a tube operated by mouth-suction. Non-mating flies were collected in the same way during the five-day sampling period. In total, 396 mating pairs, 357 non-mating females and 335 non-mating males were aspirated. In addition, a large number of flies were collected in the evening of June 29 using plastic buckets baited with crushed banana scattered about the collecting area. A second sample of wild flies was collected in a similar way on September 15, 1987.

Within three hours after collection, mating and non-mating flies were separated by sex and individually mated to virgin flies of a laboratory strain for different purposes (to be described elsewhere) in addition to thorax length measurements. Trapped flies were also separated by sex and kept in numbers of $40-50$ in $125 \mathrm{cc}$ bottles containing $25 \mathrm{cc}$ of standard cornmeal-agar-yeast medium. After approximately two weeks, thorax length was measured to the nearest $0.025 \mathrm{~mm}$ with a binocular microscope fitted with an ocular micrometer from the anterior margin of the thorax to the posterior 
tip of the scutellum, as viewed from a lateral view. All measurements were made by one of us (M.S.). Complete descriptions of the statistical tests employed can be found in Siegel (1956) and Sokal and Rohlf (1981).

\section{RESULTS}

Table 1 gives the mean and standard deviation of thorax length for males and females collected at Carboneras on five consecutive days of June 1987 and classified according to mating and non-mating flies. A consistent difference in size between these two subsamples was observed for males. In 20 out of 24 independent collections males which succeeded in mating were larger than their non-mating neighbours, and a two-tailed sign test shows that the difference is highly significant $(\boldsymbol{P}=0.002)$. The same tendency, yet less marked, was observed for females where in 16 out of 24 cases (collections
14 and 17 are excluded) mating females were larger than non-mating ones (two-tailed $P=0 \cdot 152$, sign test). On the other hand, the standard deviations of thorax length tended to be smaller in mating flies. Mating females were clearly less variable in size than non-mating ones (19 out of 24 cases, two-tailed $P=0.006$, sign test), but the difference is not statistically significant for males (16 out of 24 comparisons where there was a difference, twotailed $P=0 \cdot 152$, sign test). Comparison between the mean thorax length for the pooled sample of mating and non-mating flies (table 2 ) by means of $t$-tests shows that larger flies had a mating advantage over smaller ones for both males and females $\left(t=4.54, \mathrm{df}=649, P<0.001\right.$; for males, and $t^{\prime}=$ $2 \cdot 19, P<0 \cdot 05$; for females. $t^{\prime}$ indicates that a modified $t$-test, an approximation of the BehrensFisher test, was applied because the variance of the character was significantly higher in the nonmating females (Cochran and Cox, 1957, pp. 100101; Sokal and Rohlf, 1981, pp. 411-412)).

Table 1 Mean thorax length $\bar{X}$ (in $\mathrm{mm}$ ) and standard deviation (SD) of random samples of wild mating and non-mating flies of Drosophila buzzatii taken from rotting Opuntia ficus-indica cladodes on five consecutive days in the population of Carboneras (Spain)

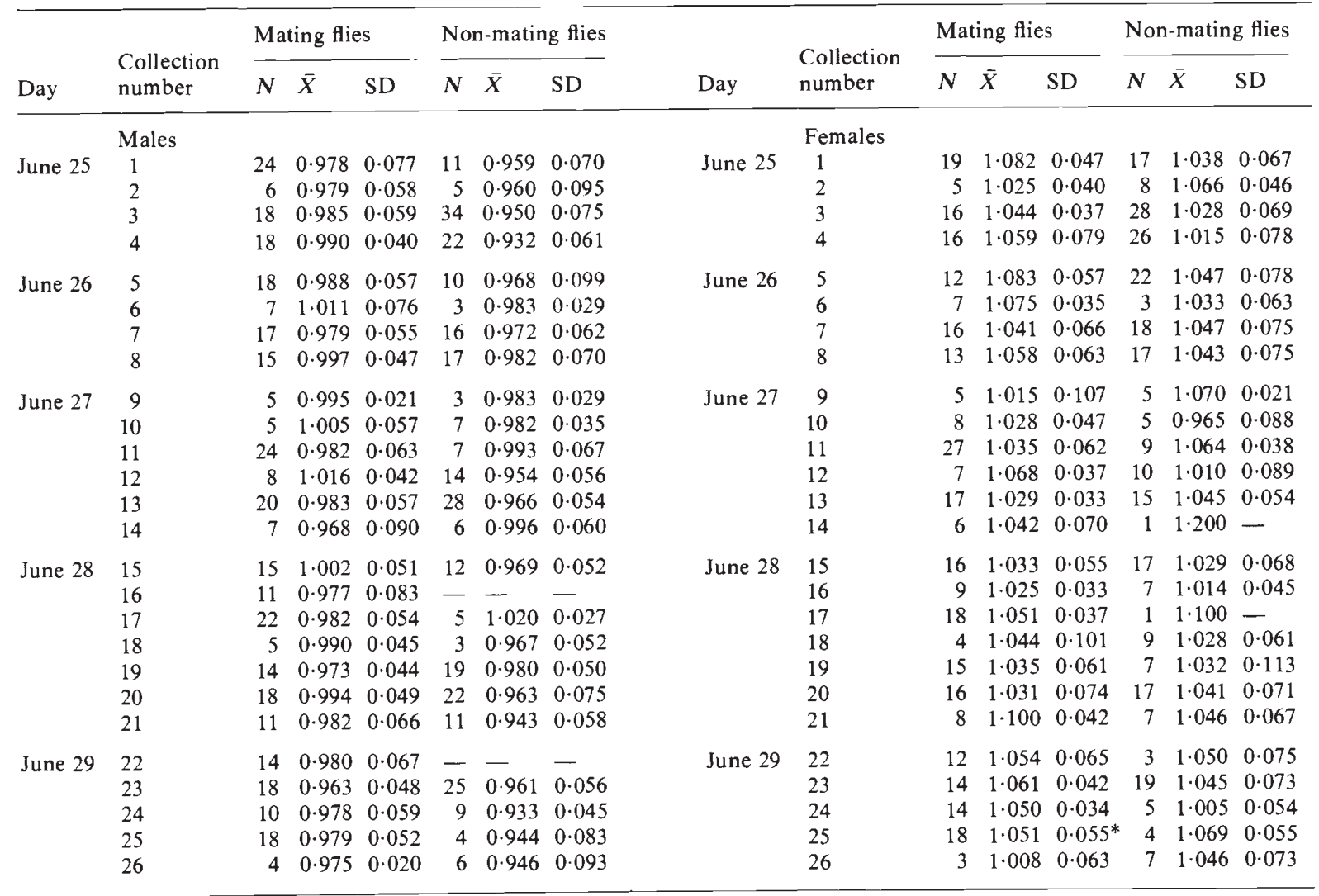

\footnotetext{
* This value is smaller than the corresponding one for non-mating females.
} 
Table 2 Means of thorax length (in $\mathrm{mm}$ ) and measures of skewness and kurtosis of four different samples of wild Drosophila buzzatii flies. The same statistics for flies reared in the laboratory under favourable conditions are given for comparison

\begin{tabular}{|c|c|c|c|c|c|}
\hline Sample & $N$ & $\begin{array}{l}\text { Mean } \\
( \pm \mathrm{SE})\end{array}$ & $\begin{array}{l}\text { Skewness } \\
\left(G_{1}\right)\end{array}$ & $\begin{array}{l}\text { Kurtosis } \\
\left(G_{2}\right)\end{array}$ & $\begin{array}{l}\text { Kolmogorov-Smirnov } \\
\text { goodness of fit } \\
\left(D_{\max }\right)\end{array}$ \\
\hline \multicolumn{6}{|l|}{ Males } \\
\hline Mating & 352 & $\begin{array}{r}0.984 \\
\pm 0.003\end{array}$ & $\begin{array}{l}-0.371 \\
\pm 0 \cdot 130\end{array}$ & $\begin{array}{r}0.385 \\
\pm 0.259\end{array}$ & $0 \cdot 137^{* *}$ \\
\hline Non-mating & 299 & $\begin{array}{r}0.963 \\
\pm 0.004\end{array}$ & $\begin{array}{l}-0.600 \\
\pm 0.141\end{array}$ & $\begin{array}{r}0.400 \\
\pm 0.281\end{array}$ & $0 \cdot 117^{* *}$ \\
\hline Trapped (June) & 218 & $\begin{array}{r}0.970 \\
\pm 0.004\end{array}$ & $\begin{array}{l}-1 \cdot 012 \\
\pm 0 \cdot 165\end{array}$ & $\begin{array}{r}1.638 \\
\pm 0.328\end{array}$ & $0 \cdot 124^{* *}$ \\
\hline Trapped (September) & 191 & $\begin{array}{r}0.967 \\
\pm 0.005\end{array}$ & $\begin{array}{l}-0.602 \\
\pm 0.176\end{array}$ & $\begin{array}{r}0.285 \\
\pm 0.350\end{array}$ & $0 \cdot 135^{* *}$ \\
\hline Laboratory reared & 150 & $\begin{array}{r}1.106 \\
\pm 0.002\end{array}$ & $\begin{array}{r}0.057 \\
\pm 0.198\end{array}$ & $\begin{array}{l}-0.570 \\
\pm 0.394\end{array}$ & $0 \cdot 243^{* *}$ \\
\hline \multicolumn{6}{|l|}{ Females } \\
\hline Mating & 321 & $\begin{array}{r}1.048 \\
\pm 0.003\end{array}$ & $\begin{array}{l}-0.409 \\
\pm 0.136\end{array}$ & $\begin{array}{r}0.348 \\
\pm 0.271\end{array}$ & $0 \cdot 106^{* *}$ \\
\hline Non-mating & 287 & $\begin{array}{r}1.037 \\
\pm 0.004\end{array}$ & $\begin{array}{l}-0.395 \\
\pm 0 \cdot 144\end{array}$ & $\begin{array}{l}-0.123 \\
\pm 0.287\end{array}$ & $0 \cdot 141^{* *}$ \\
\hline Trapped (June) & 267 & $\begin{array}{r}1.031 \\
\pm 0.004\end{array}$ & $\begin{array}{l}-0.349 \\
\pm 0.149\end{array}$ & $\begin{array}{r}0.016 \\
\pm 0.297\end{array}$ & $0 \cdot 090^{* *}$ \\
\hline Trapped (September) & 173 & $\begin{array}{r}1.039 \\
\pm 0.005\end{array}$ & $\begin{array}{l}-0.359 \\
\pm 0.185\end{array}$ & $\begin{array}{l}-0.163 \\
\pm 0.367\end{array}$ & $0 \cdot 101^{* *}$ \\
\hline Laboratory reared & 150 & $\begin{array}{r}1 \cdot 209 \\
\pm 0.002\end{array}$ & $\begin{array}{r}0.241 \\
\pm 0.198\end{array}$ & $\begin{array}{r}0.988 \\
\pm 0.394\end{array}$ & $0 \cdot 268^{* *}$ \\
\hline
\end{tabular}

${ }^{* *} P<0 \cdot 01$.

Before discussing the implications of these results, a possible source of bias due to the collecting method must be considered. Single flies were usually more active and difficult to catch using an aspirator than flies engaged in copulation. This circumstance might produce the result we observed if larger flies were less frequently collected than smaller ones. In order to test this possibility we compared the thorax length of the non-mating and bait-trapped individuals collected in June 1987 (table 2). No statistically significant differences were found between the means of these two samples $(t=1 \cdot 22, \mathrm{df}=515, P>0 \cdot 05$; and $t=0.97$, $\mathrm{df}=552, P>0 \cdot 05$; for males and females, respectively), and the variances were also similar. Therefore, we conclude that the collecting method did not bias the average thorax length of the nonmating flies. Table 2 gives estimates of skewness and kurtosis and Kolmogorov-Smirnov goodnessof-fit to test deviations from normality for the three samples collected in June 1987. It is evident that thorax length distributions depart in all three cases from normality, and no simple transformation (e.g., a log transformation) makes the data to be normally distributed. Hence, to strengthen our conclusions, we used non-parametric statistical tests to compare the thorax length of the three different samples of wild-caught flies. The KruskalWallis statistic confirmed that mating flies are significantly larger than non-mating and trapped ones ( $H=17 \cdot 26, P<0.001$; for males and $H=9.62$, $P<0.01$; for females).

Table 2 also gives the mean thorax size of the sample of $D$. buzzatii collected at Carboneras in September 1987 by means of banana baits and their offspring raised in the laboratory at $23^{\circ} \mathrm{C}$ under uncrowded, optimal conditions. The mean size of the wild flies did not differ from that of the analogous sample collected in June of the same year $(t=0 \cdot 43, \mathrm{df}=407, P>0.05$; and $t=1 \cdot 19, \mathrm{df}=$ $438, P>0.05$; for males and females, respectively). Thus, body size seems to be fairly stable through the summer in the Carboneras population. On the other hand, it can be seen from table 2 that the distributions of thorax length for the wild flies tended to be leptokurtic and highly skewed in the direction of smaller size, and the mean size was substantially lower whereas the variance was about ten times that of the laboratory reared flies. These results are comparable to those obtained by McFarquhar and Robertson (1963) on D. subob- . scura, by David (1979) on D. melanogaster and by 
Robertson (1987) on D. buzzatii (for an apparent exception to this trend see Sokoloff, 1957). The usual interpretation to these observations is that the environmental conditions encountered by wild larvae are extremely variable and suboptimal compared to those in the laboratory. Most of the increased variation in size can be attributed to differences in larval food supply, yet fluctuations in temperature may also be important in some cases. Food shortage during larval life is probably a major stress factor in the environment for many Drosophila species (Robertson, 1987). Cactophilic Drosophila species feed upon the microorganisms associated with the decaying tissues of cacti, which concentrate protein, vitamins, sterols and other essential nutrients from the substrate (Sang, 1978) and produce volatile compounds that act as stimuli for larvae and adults (Fogleman, 1982). A high level of variation among rots for yeast species present and total yeast density has been found for both agria and organpipe cacti in the Sonoran Desert (Starmer, 1982; and Fogleman and Starmer, 1985) and the same has been observed for Opuntia ficus-indica at the locality of Carboneras (F. Peris, personal communication). Although suboptimal diets are the rule under larval crowding, variation in larval food supply does not necessarily involve differences in the level of competition experienced by the larvae (McFarquhar and Robertson, 1963).

\section{DISCUSSION}

The difference we observed for mean body size between mating and non-mating flies could be plainly interpreted as due to directional selection for mating success on this quantitative trait, although some stabilizing selection might be also involved for females in view of the consistent difference in the standard deviations among mating and non-mating females (table 1). Directional sexual selection in natural populations for morphological characters related to body size has been documented in a variety of organisms, including moths (Mason, 1969); beetles (McCauley and Wade, 1978; Mason, 1980; McLain, 1981, 1982); butterflies (Wickman, 1985); toads (Wilburg et al., 1978; Davies and Halliday, 1979; Fairchild, 1981; Halliday, 1983); frogs (Howard, 1979, 1980; Berven, 1981; Arnold, 1983; Arnold and Wade, 1984b; Howard and Kluge, 1985; Ryan, 1983; Robertson, 1986); and finches (Price, 1984). In these studies body size was found to be positively correlated with mating success and in the bullfrog, Rana catesbiana, sexual selection accounted for 75 per cent of the total selection differential shifting the mean male size distribution 0.63 standard deviations (Arnold and Wade, 1984b). On the other hand, stabilizing selection seems to be less frequent (Endler, 1986), yet a few examples do exist (Mason, 1964; Scheiring, 1977; McCauley, 1979; Fincke, 1986).

Limitations imposed by the biology of $D$. buzzatii such as difficulties associated with recognizing and recapturing adults, indentifying the size of the broods and identifying male paternity, do not allow to measure the life-time reproductive success nor the opportunity for selection of this species in the field. Consequently, answers to some critical questions related to theories of sexual selection and life histories cannot be given at the moment. Owing to the lack of information of natural selection on body size during particular segments of the life cycle, it would be rash to interpret our results as due solely to mating success and variance in adult survivorship might also be important (McCauley, 1983; Fincke, 1986; Koenig and Albano, 1987). In addition, it would be very valuable to know whether male mating success is agespecific in our population.

When dealing with quantitative characters the process of selection may be decomposed into phenotypic selection and genetic response. Selection intensity can be measured as the standardized difference between the character means in the population before and after selection (Falconer, 1981). Assuming that our non-mating flies accurately represent the population before selection, we can estimate the selection intensity in the $D$. buzzatii population as 0.34 in males and 0.16 in females (average $0 \cdot 25$ ). On the other hand, response to selection is defined as the difference of mean phenotypic value between the offspring of the selected parents and the entire parental generation before selection (Falconer, 1981). Information about inheritance of the character is obviously required in order to predict the response to selection. Roff and Mousseau (1987) have recently summarized the heritability estimates for thorax length in Drosophila species (mainly $D$. melanogaster). The range in $h^{2}$ is from $0 \cdot 15$ up to $0 \cdot 50$, although Robertson (1987) infers higher heritabilities (about $0 \cdot 60-0 \cdot 70$ ) for two out of three populations of D. buzzatii from Australia. However, as environmental variance of body size is greatly increased by heterogeneity of larval habitats in D. buzzatii-i.e., the rotting Opuntia cladodes-the heritability of this phenotypic trait in the field must be much lower than that measured under homogeneous laboratory conditions, and the genetic response will be correspondingly lower. 
If there is heritable variation for body size in the Carboneras population, sexual selection will change the population mean unless opposed by selection for a different component of fitness, such as viability or developmental time.

Is $D$. buzzatii slowly increasing in body size in the colonized population of Carboneras? The information we have so far (table 2) is clearly inadequate to answer this question, yet the answer is probably no. Body size is strongly integrated with life history traits and the two key parameters to Lotka's theory, $l_{x}$ (probability of survival to age $x$ ) and $m_{x}$ (number of female offspring produced at age $x$ ), are functions of this quantitative trait in ectoterms (Roff, 1981, 1986). Much evidence indicates that fecundity and other adult fitness components are positively correlated with body size in Drosophila, but so does development time and, therefore, generation time (Robertson, 1957a, $b$; 1960). Hence, a trade-off between fitness components is expected according to theories about the evolution of life histories, although apparent conflicts between sexual selection and life-history theories exist (Taylor et al., 1987). A stable equilibrium for body size can be attained if there is a cost associated with either the achievement of a large size or the fighting with conspecifics similar in size (Maynard Smith and Brown, 1986). Some experimental results provide support for the existence of an equilibrium distribution of size in D. melanogaster when sexual selection is opposed by earlier selection episodes, giving rise to the proposition that larval mortality increases with body size (Wilkinson, 1987). We have previously shown that there are fitness differences among second-chromosome karyotypes for egg-to-thirdinstar larva viability component in the population of D. buzzatii at Carboneras (Ruiz et al., 1986; Santos et al., in press), but we did not study the relationship, if any, between body size and inversion polymorphism for this species. It would be very interesting to correlate both characters and to know (providing that there is heritable variation for body size) if genetically large flies suffer higher mortality in the Opuntia rots.

Bateman (1948) showed that there is a sexual difference in fitness variances for mating success in $D$. melanogaster, largely due to the fact that mating success is more variable in males than in females (a mathematical demonstration of Bateman's results is given in Wade and Arnold (1980)). While virtually all females mate in Drosophila populations, some males can achieve several matings and others none. Male reproductive success is determined by the number of matings achieved whereas female reproductive potential is determined by the number of eggs laid. Thus, it is not clear that female mating success is an important fitness component in Drosophila. However, variance in the number of matings achieved by females could exist if female remating is relatively frequent and males, having a wide choice, invest courtship time in more desirable females.

Males or females could enhance their reproductive success if they are able to choose their matings by means of (a) male choice: if males choose from a variety of females and mate with those who are larger and, consequently, have a higher fecundity (Robertson, 1957a,b); or (b) female choice: if females choose from a variety of males and mate with those who will confer a higher quality to the offspring (Partridge, 1980; Taylor et al., 1987). The current belief is that female flies of Drosophila choose their mates (Spiess, 1982), yet some authors disagree (e.g., Wilkinson, 1987, p. 19). Nevertheless, Markow (1982) points out that the putative role of male choice in cactophilic Drosophila species deserves some consideration. A striking characteristic of the mating systems of these species is the frequent female remating, which assures a ready supply of sperm and, perhaps most important, that females gain nutrients from males (Markow and Ankney, 1984; Starmer et al., in press). If male choice exists in D. buzzatii, we would predict that males should prefer larger females over smaller ones. Moreover, positive assortative mating would occur given that the largest, most successful males should be able to mate the largest, most fertile females. Mating females are, on average, larger than non-mating and trapped ones but Kendall's and Spearman's coefficients of rank correlation for the body size of mating pairs are not statistically different from $0 \quad\left(\tau=-0.041, P>0.05 ;\right.$ and $r_{\mathrm{s}}=-0.054, \quad P>$ $0.05)$. Thus positive assortative mating does not occur in our sample. Hence, we cannot conclude that male choice takes place in the population of D. buzzatii at Carboneras and the reasons for the difference we observed between mating and nonmating females remain to be known. Our results could be best interpreted as due to the vigour or general activity levels of larger flies which are more likely to encounter suitable mates than smaller ones, although differences in size could exist among age-classes.

\footnotetext{
Acknowledgements We thank Professor W. B. Heed who has been generous with his knowledge and experience during his sabbatical leave at our lab. This work was supported by grant \#PB85-0071 to A. Fontdevila from the Comisión Interministerial de Ciencia y Tecnologia (CICYT), Spain.
} 


\section{REFERENCES}

ANDERSSON, M. 1982. Female choice selects for extreme tail length in a widowbird. Nature, 299, 818-820.

ARNOLD, S. J. 1983. Sexual selection: the interface of theory and empiricism, In Bateson, P. (ed.) Mate Choice, Cambridge Univ. Press, pp. 67-107.

ARNOLD, S. J. AND WADE, M. J. $1984 a$. On the measurement of natural and sexual selection: theory. Evolution, 38, 709-719.

ARNOLD, S. J. AND WADE, M. J. $1984 b$. On the measurement of natural and sexual selection: applications. Evolution, $38,720-734$.

BARKER, J. S. F. 1977. Cactus-breeding Drosophila: A system for the measurement of natural selection. In Christiansen, F. B. and Fenchel, T. M. (eds) Measuring Selection in Natural Populations, Springer-Verlag, Berlin, pp. 403430.

BARKER, J. S. F. AND EAST, P. D. 1980. Evidence for selection following perturbation of allozyme frequencies in a natural population of Drosophila. Nature, 284, 166-168.

BARKER, J. S. F. AND FREDLINE, D. K. 1985. Reproductive biology of Drosophila buzzatii. Dros. Inf. Serv., 61, 28-32.

BAteman, A. J. 1948. Intra-sexual selection in Drosophila. Heredity, 2, 349-368.

BERVEN, K. A. 1981. Mate choice in the wood frog, Rana sylvatica. Evolution, 35, 707-722.

BUNDGAARD, J. AND CHRISTIANSEN, F. B. 1972. Dynamics of polymorphisms. I. Selection components in an experimental population of Drosophila melanogaster. Genetics, $71,439-460$.

COCHRAM, W. C. AND COX, G. M. 1957. Experimental Designs, 2nd ed., John Wiley \& Sons, New York.

DARWIN, C. R. 1871. The Descent of Man, and Selection in Relation to Sex. John Murray, London.

DAVID, J. R. 1979. Utilization of morphological traits for the analysis of genetic variability in wild populations. Aquilo Ser. Zool., 20, 49-61.

DAVIES, N. B. AND hAllidAY, T. R. 1979. Competitive mate searching in male common toads, Bufo bufo. Anim. Behav., $27,1253-1267$.

EANES, W. F., GAFFNEY, P. M., KOEHN, R. K. AND SIMON, C. M. 1977. A study of sexual selection in natural populations of the milkweed beetle Tetraopes tetraophthalmus, In Christiansen, F. B. and Fenchel, T. M. (eds) Measuring Selection in Natural Populations, Springer-Verlag, Berlin, pp. $49-64$.

ENDLER, J. A. 1986. Natural Selection in the Wild. Princeton Univ. Press, Princeton, New Jersey.

EWING, A. W. 1983. Functional aspects of Drosophila courtship. Biol. Rev., 58, 275-292.

EWING, L. S. AND EWING, A. W. 1984. Courtship in Drosophila melanogaster: behaviour of mixed sex groups in large observation chambers. Behaviour, 90, 184-202.

FAIRCHILD, L. 1981. Mate selection and behavioral thermoregulation in Fowler's toads. Science, 212, 950-951.

FALCONER, D. S. 1981. Introduction to Quantitative Genetics, 2nd ed. Longman, London.

FINCKE, O. M. 1986. Lifetime reproductive success and the opportunity for selection in a nonterritorial damselfly (Odonata: Coenagrionidae). Evolution, 40, 791-803.

FOGLEMAN, J. C. 1982. The role of volatiles in the ecology of cactophilic Drosophila, In Barker, J. S. F. and Starmer, W. T. (eds) Ecological Genetics and Evolution: The CactusYeast-Drosophila Model System, Academic Press, Sydney, pp. 191-206.
FOGLEMAN, J. C. AND STARMER, W. T. 1985. Analysis of the community structure of yeasts associated with the decaying stems of cactus. 11I. Stenocereus thurberi. Microb. Ecol., 11, 165-173.

HALLIDAY, T. 1983. Do frogs and toads choose their mates? Nature, 306, 226-227.

HOUDE, A. E. 1987. Mate choice based upon naturally occurring color-pattern variation in a guppy population. Evolution, 41, 1-10.

HOWARD, R. D. 1979. Estimating reproductive success in natural populations. Amer. Natur., 114, 221-231.

HOWARD, R. D. 1980. Mating behaviour and mating success in wood frogs, Rana sylvatica. Anim. Behav., 28, 705-716.

HOWARD, R. D. AND KLUGE, A. G. 1985. Proximate mechanisms of sexual selection in wood frogs. Evolution, 39, 260-277.

KNOPPIEN, P. 1985. Rare male mating advantage: a review. Biol. Rev., 60, 81-117.

KOENIG, W. D. AND ALBANO, S. S. 1987. Lifetime reproductive success, selection, and the opportunity for selection in the white-tailed skimmer Plathemis lydia (Odonata: Libellulidae). Evolution, 41, 22-36.

LANDE, R. 1980. Sexual dimorphism, sexual selection, and adaptation in polygenic characters. Evolution, 34, 294-305.

MAJERUS, M. E. N. 1986. The genetics and evolution of female choice. Trends Ecol. Evol, 1, 1-7.

MAJERUS, M. E. N., O'DONALD, P. AND WEIR, J. 1982. Female mating preference is genetic. Nature, 300, 521-523.

MARKOW, T. A. 1982. Mating systems of cactophilic Drosophila, In Barker, J. S. F. and Starmer, W. T. (eds) Ecological Genetics and Evolution: The Cactus-Yeast-Drosophila Model System. Academic Press, Sydney, pp. 273-287.

MARKOW, T. A. AND ANkNEY, P. F. 1984. Drosophila males contribute to oogenesis in a multiple mating species. Science, 224, 302-303.

MASON, L. G. 1964. Stabilizing selection for mating fitness in natural populations of Tetraopes. Evolution, 18, 492-497.

MASON, L. G. 1969. Mating selection in the California Oak moth (Lepidoptera, Dioptidae). Evolution, 23, 55-58.

MASON, L. G. 1980. Sexual selection and the evolution of pair-bonding in soldier beetles. Evolution, 34, 174-180.

MAYNARD SMITH, J. AND BROWN, R. L. W. 1986. Competition and body size. Theor. Pop. Biol, 30, 166-179.

McCAULEY, D. E. Geographic variation in body size and its relation to the mating structure of Tetraopes populations. Heredity, 42, 143-148.

MCCAULEY, D. E. 1983. An estimate of the relative opportunities for natural and sexual selection in a population of milkweed beetles. Evolution, 37, 701-707.

McCAUlEY, D. E. AND WADE, M. J. 1978. Female choice and the mating structure of a natural population of the soldier beetle, Chauliognathus pennsylvanicus. Evolution, 32, 771775 .

McFARQUHAR, A. M. AND ROBERTSON, F. W. 1963. The lack of evidence for co-adaptation in crosses between geographical races of Drosophila subobscura Coll. Genet. Res., 4, 104-131.

MCLAIN, D. K. 1981. Interspecific interference competition and mate choice in the soldier beetle, Chauliognathus pennsylvanicus. Behav. Ecol. Sociobiol., 9, 65-66.

McLAIN, D. K. 1982. Density dependent sexual selection and positive phenotypic assortative mating in natural populations of the soldier beetle, Chauliognathus pennsylvanicus. Evolution, 36, 1227-1235.

O'donald, P. 1980. Genetic Models of Sexual Selection. Cambridge Univ. Press, Cambridge.

PARTRIDGE, I. 1980. Mate choice increases a component of offspring fitness in fruit flies. Nature, 283, 290-291. 
PARTRIDGE, L., HOFFMAN, A. AND JONES, J. S. 1987. Male size and mating success in Drosophila melanogaster and Drosophila pseudoobscura under field conditions. Anim. Behav., 35, 468-476.

PATTERSON, J. T. 1947. The insemination reaction and its bearing on the problem of speciation in the mulleri subgroup. Univ. Texas Publ., 4720, 41-77.

PRICE, T. D. 1984. Sexual selection on body size, territory and plumage variables in a population of Darwin's finches. Evolution, 38, 327-341.

PROUT, T. 1971. The relation between fitness components and population prediction in Drosophila. I. The estimation of fitness components. Genetics, 68, 127-149.

READ, A. F. 1986. Female mate choice in pied flycatchers: an answer and a problem. Trends Ecol. Evol, , 1, 85 .

ROBERTSON, F. W. 1957a. Studies in quantitative inheritance. $\mathrm{X}$. Genetic variation of ovary size in Drosophila. J. Genet., $55,410-427$.

ROBERTSON, F. W. 1957 b. Studies in quantitative inheritance. XI. Genetic and environmental correlation between body size and egg production in Drosophila melanogaster. $J$. Genet., 55, 428-443.

ROBERTSON, F. W. 1960. The ecological genetics of growth in Drosophila. I. Body size and development time on different diets. Genet. Res., 1, 288-304.

ROBERTSON, F. W. 1987. Variation of body size within and between wild populations of Drosophila buzzatii. Genetica, $72,111-125$.

ROBERTSON, J. G. M. 1986. Female choice, male strategies and the role of vocalizations in the Australian frog Uperoleia rugosa. Anim. Behav., 34, 773-784.

ROFF, D. A. 1981. On being the right size. Amer. Natur., 118 , $405-422$.

ROFF, D. A. 1986. Predicting body size with life history models. BioScience, 36, 316-323.

ROFF, D. A. AND MOUSSEAU, T. A. 1987. Quantitative genetics and fitness: lessons from Drosophila. Heredity, 58, 103-118.

ROIG, E., RUIZ, A. AND FONTDEvila, A. 1986. Análisis comparativo del comportamiento de apareamiento de las especies de Drosophila del cluster buzzatii. XXII. Jornadas de Genética Luso-Españolas. Oviedo (Spain).

RUiz, A., FONTDEVIla, A., SANTOS, M., SEOANE, M. AND TORROJA, E. 1986. The evolutionary history of Drosophila buzzatii. VIII. Evidence for endocyclic selection acting on the inversion polymorphism in a natural population. Evolution, 40, 740-755.

RYAN, M. J. 1983. Sexual selection and communication in a neotropical frog, Physalaemus pustulosus. Evolution, 37, 261-272.

SANG, J. H. 1978. The nutritional requirements of Drosophila. In Ashburner, M. and Wright, T. R. F. (eds) The Genetics and Biology of Drosophila, Vol. 2a, Academic Press, London, pp. 159-192.

SANTOS, M., RUIZ, A. AND FONTDEVILA, A. 1988. The evolutionary history of Drosophila buzzatii. XIII. Random differentiation cannot explain all the observed chromosomal variation in a structured natural population. Amer. Natur. (in press).
SCHEIRING, J. F. 1977. Stabilizing selection for size as related to mating fitness in Tetraopes. Evolution, 31, 447-449.

SEARCY, W. A. 1982. The evolutionary effects of mate selection. Ann. Rev. Ecol. Syst., 13, 57-85.

SEMLER, D. E. 1971. Some apsects of adaptation in a polymorphism for breeding colours in the threespine stickleback (Gasterosteus aculeatus). J. Zool, 165, 291-302.

SIEGEL, S. 1956. Non-Parametric Statistics for the Behavioral Sciences. McGraw-Hill Co., New York.

SOKAL, R. R. AND ROHLF, F. J. 1981. Biometry, 2nd ed. W. H. Freeman, New York.

SOKOLOFF, A. 1957. Discussion after paper by A. Milne: "Theories of natural control of insect populations". Cold Spring Harbor Symp. quant. Biol., 22, 268-271.

SPIESS, E. B. 1970. Mating propensity and its genetic basis in Drosophila, In Hecht, M. K. and Steere, W. C. (eds) Essays in Evolution and Genetics in Honor of Theodosius Dobzhansky. North-Holland, Amsterdam, pp. 315-379.

SPIESS, E. B. 1982. Do female flies choose their mates? Amer. Natur., 119, 675-693.

SPIETH, H. T. 1952. Mating behavior within the genus Drosophila (Diptera). Bull. Amer. Museum Nat. Hist., 99, 395-474.

SPIETH, H. T. AND RINGO, J. M. 1983. Mating behavior and sexual isolation in Drosophila, In Ashburner, M., Carson, H. L. and Thompson, Jr. J. N. (eds) The Genetics and Biology of Drosophila, Vol. 3c, Academic Press, London, pp. 223-284.

STARMER, W. T. 1982. Analysis of the community structure of yeasts associated with the decaying stems of cactus. I. Stenocereus gummosus. Microb. Ecol., 8, 71-81.

STARMER, W. T., PERIS, F. AND FONTDEVILA, A. 1988. The transmission of yeast by Drosophila buzzatii during courtship and mating and through the pupal period. Anim. Behav. (in press).

TAYLOR, C. E., PEREDA, A. D. AND FERRARI, J. A. 1987. On the correlation between mating success and offspring quality in Drosophila melanogaster. Amer. Natur., 129, 721 729.

THORNHILL, R. 1976. Sexual selection and nuptial feeding behavior in Bittacus apicalis (Insecta: Mecoptera). Amer. Natur., 110, 529-548.

THORNHILL, R. 1980. Mate choice in Hylobittacus apicalis (Insecta: Mecoptera) and its relation to some models of female choice. Evolution, 34, 519-538.

THORNHILl, R. 1983. Cryptic female choice and its implications in the scorpionfly Harpobittacus nigriceps. Amer. Natur., 122, 765-788.

WADE, M. J. AND ARNOLD, S. J. 1980. The intensity of sexual selection in relation to male sexual behavior, female choice, and sperm precedence. Anim. Behav., 28, 446-461.

WICKMAN, P. 1985. Territorial defence and mating success in males of the small heath butterfly, Coenonympha pamphilus L. (Lepidoptera: Satyridae). Anim. Behav., 33, 1162-1168.

WILBURG, H. M., RUBENSTEIN, D. I. AND FAIRCHILD, L. 1978. Sexual selection in toads: the roles of female choice and male body size. Evolution, 32, 264-270.

WILKINSON, G.S. 1987. Equilibrium analysis of sexual selection in Drosophila melanogaster. Evolution, 41, 11-21. 